\title{
DINÂMICA DA CALAGEM SUPERFICIAL EM UM LATOSSOLO VERMELHO DISTRÓFICO(1)
}

\author{
J onez Fidalski ${ }^{(2)}$ \& Cássio Antonio Tormena ${ }^{(3)}$
}

\begin{abstract}
RESUMO
As alterações químicas do solo após a calagem superficial variam de acordo com o tempo e precipitações pluviais. Com o objetivo de avaliar as alterações das características químicas de um Latossolo Vermel ho distrófico textura média de camada superficial arenosa, foi instalado um experimento em blocos ao acaso, com quatro doses de calcário dolomítico $(0 ; 2,4 ; 4,8$ e 7,2 t ha-1) e três repetições, em 1999, no município de Alto Paraná, região noroeste do Paraná. O calcário foi distribuído sobre resíduos de Brachiaria decumbens nas entrelinhas de um pomar de laranja em formação. As parcelas experimentais foram constituídas de $310 \mathrm{~m}^{2}$, compostas por 15 plantas em três linhas com cinco plantas cada. As amostras de solo foram coletadas nas entrelinhas das três plantas centrais da parcela nas camadas de $0-0,05,0,05-0,10,0,10-0,20,0,20-0,40$ e $0,40-0,60 \mathrm{~m}$ de profundidade, aos 4, 12, 18, 24, 31 e 37 meses após a distribuiç̧ão do calcário, correspondendo alternadamente às épocas de amostragens de solo em períodos de alta e baixa precipitação pluvial. As análises de variância foram efetuadas por meio do modelo matemático de blocos ao acaso no esquema de parcela subsubdividida com medidas repetidas no tempo (ano, época do ano em função da precipitação pluvial e doses de calcário), utilizadas nas análises de regressões pela técnica dos polinômios ortogonais. Os resultados mostraram que a máxima alteração das características químicas do solo foi obtida a partir de doses de calcário superiores ao dobro da necessidade de calcário, convencionalmente determi nada pelo método de saturação por bases para elevá-la a $70 \%$, na profundidade de 0,20 m. A amostragem de solo após o período de maior precipitação pluvial foi indispensável ao ajuste dos dados da saturação por bases na camada de 0-0,05 m. As alterações dos teores de $\mathrm{Ca}^{2+}$ limitaram-se à camada de 0-0,10 m, enquanto os teores de $\mathrm{Mg}^{2+}$ aumentaram progressivamente do primeiro ao terceiro ano a 0 $0,60 \mathrm{~m}$ de profundidade. Os teores de $\mathrm{Mg}^{2+}$ mantiveram-se associados à correção da acidez do solo (pH e H + Al) e à elevação dos valores de saturação por bases na profundidade de $0,10-0,20 \mathrm{~m}$, na qual foi constatada a menor relação de $\mathrm{Ca}^{2+}$ $\mathrm{Mg}^{2+}(1,06)$. A máxima resposta da calagem superficial ocorreu no terceiro ano da aplicação da calagem superficial e na camada de 0-0,10 m identificada pelos
\end{abstract}

(1) Recebido para publicação em abril de 2003 e aprovado em dezembro de 2004.

(2) Pesquisador do Instituto Agronômico do Paraná - IAPAR. Estação Experimental de Paranavaí, e Doutorando em Sol os e Nutrição de Plantas na Universidade Estadual de Maringá - UEM. Caixa Postal 564, CEP 87701-970 Paranavaí (PR). E-mail: fidalski@iapar.br

(3) Professor Adjunto do Departamento de Agronomia, UEM. Bolsista do CNPq. E-mail: catormena@uem.br 


\begin{abstract}
modelos de regressão quadrática, momento em que se identificou o estabelecimento de uma frente de alcalinização na camada de 0,10-0,20 m por meio dos modelos de regressão linear. 0 método empregado de parcelas subsubdi vididas no tempo permitiu a descrição da di nâmica da calagem no perfil do solo.
\end{abstract}

\author{
Termos de indexação: acidez, pH, cálcio, magnésio, saturação por bases, subsolo, \\ mobilidade de cátions.
}

\title{
SUMMARY: DYNAMICS OF SURFACE LIMING IN A TYPIC HAPLORTHOX
}

\begin{abstract}
Alterations in soil chemical properties after liming depend on the frequency of soil sampling and rainfall. This study evaluated such alterati ons in a Typic Haplorthox (R hodic Ferralsol) with a sandy-l oam superficial layer. Theexperiment had a completely randomized block design, with four dolomitic limerates $\left(0,2.4,4.8\right.$, and $\left.7.2 \mathrm{t}^{-1} \mathrm{a}^{-1}\right)$ and threereplicates. The experiment was carried out in Alto Parana in northwestern Parana state (southern Brazil). Limewas broadcast on the soil surface over Brachiaria decumbens grass residues in-between rows of a young orangeplantation. The experimental plots consisted of an area of $310 \mathrm{~m}^{2}$ with 15 orange plants each ( 3 rows and 5 plants per row). Soil samples were collected in-between the rows of 3 central orange plants at depths of $0-0.05 ; 0.05-0.10$; $0.10-0.20 ; 0.20-0.40$; and $0.40-0.60$ meter at $4,12,18,24,31$, and 37 months after liming. This sampling times corresponded to alternated rainy and dry seasons of the region. The analysis of variance was performed based on a completerandomized block desi gn in a splitsplit-pl ot scheme with repeated measures over time (years, rainfall season and lime rates), which wereused in theregression analyses through orthogonal polynomial models. Results showed that maximum al terations in the soil chemical properties were obtained with lime rates twice as high as those calculated to raisethe soil basesaturation to $70 \%$ at a depth of $0.20 \mathrm{~m}$. Soil sampling after the high rainfall period proved important to adjust the base saturation data in the $0-0.05$ m layer. Ca concentration only varied in the $0-0.10 \mathrm{~m}$ layer, whilethose of $\mathrm{Mg}$ varied progressively from the first to thethird year in the 0-0.60 mlayer. $\mathrm{Mg}$ concentrations were associated to the soil acidity correction $(\mathrm{pH}$ and $\mathrm{H}+\mathrm{Al})$ and to the increment of the base saturation values in the $0.10-0.20 \mathrm{~m}$ layer, where it was found the lowest $\mathrm{Ca} / \mathrm{Mg}$ ratio (1.06). The most pronounced response to surfaceliming was observed in the third year after surface liming (0-0.10 $\mathrm{m}$ deep) identified by quadratic regression models. At the same time linear regression models identified the establishment of a alkalinization front in the $0.10-0.20$ m soi l layer. Themethodol ogy of spl it-split-pl ot design with repeated measures over timeallowed thedescription of the superficial limedynamics al ong the time.
\end{abstract}

Index terms: acidity, pH, calcium, magnesium, base saturation, subsoil, cation mobility.

\section{INTRODUÇÃO}

Os solos originários da formação Caiuá, no nor oeste do Paraná ocupam 3,2 mil hões dehectares e representam $16 \%$ da área do Estado (Sá \& Caviglione, 1999), dos quais aproximadamente $70 \%$ são ocupados por pastagens. A conveniência ou não de se aplicar calcário vem sendo questionada há mais de duas décadas, segundo Machado et al. (1979). Esses autores verificaram em um Latossolo Vermelho distrófico que a produção de doze forrageiras nãoapresentou resposta à dose de $2 \mathrm{t} \mathrm{ha}^{-1}$ de calcário. Também no estudo relacionado com nutrição de plantas forragei ras desenvol vido em casa de vegetação, constatou-se que esse solo supriu as necessidades nutricionais das braquiária e col onião por $\mathrm{Ca}$ e $\mathrm{Mg}$, mas não atendeu às exigências nutricionais dessas forrageiras com os demais macronutrientes (Faquin et al., 1995; Hoffmann et al., 1995).

Na última década, o estabel ecimento de pomares de Iaranja nesses solos promoveu a retomada de estudos da calagem, dada a exigência dos citros por Ca e Mg. Rêgo (1997), avaliando a aplicação e a reaplicação superficial de calcário e gesso agrícola efetuada no terceiro e no quarto ano de um pomar de Iaranjeira Pêra em um Latossolo Vermelho distrófico, verificou que houve baixa reação do calcário, enquanto o gesso agrícola promoveu a lixiviação do Mg presenteno solo. Experimentos com 
a incorporação de cal cário foram desenvolvidos nesses solos na cultura de mandioca durante 11 meses (Fidalski, 1999). Os resultados não apresentaram alterações das características químicas que pudessem caracterizar a reação do cal cário. Nesses experimentos, não foram obtidas respostas da produção de frutos delaranja e de raízes de mandioca à calagem, independentemente da maior resposta agronômica à calagem dos citros em relação à mandioca (Gomes, 1987; Quaggio, 1996).

Por meio de um levantamento nutricional com amostras de sol o e de fol ha dos pomares de laranja em produção, Fidalski \& Auler (1997) e Fidalski et al. (2000) comprovaram a deficiência nutricional por $\mathrm{Mg}$ e a dependência da produção de frutos por $\mathrm{Ca}$. Os teores de Ca, Mg e a saturação por bases do solo foram crescentes do plantio até à primeira colheita de frutos, seguida do decréscimo até a quinta safra, resultandonuma saturação por bases média de $40 \%$, índice semel hante àquele das pastagens existentes antes do estabelecimento dos pomares. A redução da saturação por bases deveu-se à baixa reaplicação de calcário, constatada pelas freqüências de reaplicação de calcário após a primeira e a quinta col heita de frutos, respectivamente, em 29 e $75 \%$ dos pomares de laranja (F idalski \& Auler, 1997).

A baixa eficiência da calagem nesses solos e a elevada exigência da cultura da laranja por Ca e Mg implicaram a reaplicação de cal cário para evitar deficiências nutricionais e possíveis reduções do potencial de produtividade dos pomares. As informações técnicas geradas em solos originários da formação sedimentar ou do basalto paranaense (Pavan, 1992; Oliveira \& Pavan, 1996; Caires et al., 2000) não são apl icáveis aos sol os da formação Caiuá da região noroeste do Paraná, por apresentarem uma camada arável com granulometria pertencente à classe textural arenosa, com baixa acidez potencial, saturação por alumínio em média de $10 \%$, baixa disponibilidade de cátions eteor médio de C orgânico de $0,56 \mathrm{~g} \mathrm{~kg}^{-1}$ (Fidalski, 1997).

Nesse contexto, duas hipóteses relativas à ineficiência da calagem superficial nesses solos podem ser destacadas: o Ca e Mg estariam sendo lixiviados em razão da textura arenosa da camada superficial do sol o, ou o cal cário estaria apresentando reação lenta. M Meda et al. (2002), em um estudo em condições de laboratório, descartaram a primeira hi pótese, visto quea apl icação de cal cário dol omítico na superfície do sol o seguida da lixiviação com água destilada não alterou a composição química das camadas inferiores do solo, tendo grande parte dos carbonatos de Ca e Mg permanecido na superfície do solo. A segunda hipótese foi constatada em estudos brasileiros com calagem superficial mesmo em solo arenoso por Rheinheimer et al. (2000a) e Gatiboni et al. (2003). Castilhos et al. (2000) em pastagens obtiveram resposta da calagem superficial até à profundidade de $0,03 \mathrm{~m}$ após 18 meses da aplicação do cal cário. Recentemente, Oliveira et al .
(2003), em estudo derecuperação deuma Brachiaria decumbens por meio da calagem superficial e incorporada, não al cançaram os val ores de saturação por bases testadas de 40, 50 e $80 \%$, após dois anos, na camada de 0-0,20 m de profundidade, tendo sido obtido o valor máximo de $58 \%$ na camada de 0-0,05 m. A calagem superficial estudada em plantio direto sobre áreas originalmente de pastagens de campo nativo também promoveu alterações das características químicas na camada de 0,05 e 0,23 m de profundidade (Rheinheimer et al., 2000a; Petrere \& Anghioni, 2001).

Por serem as condições de umidade do solo importantes para a dissolução do cal cário, verifica-se, dentreos estudos decal agem superficial desenvol vido no Brasil, somente o relato metodológico, descrito por Moreira et al. (2001), das preci pitações de 1.174 e $1.305 \mathrm{~mm}$, respectivamente, após a primeira e a segunda amostragem de solo, realizadas em um interval o de 41 dias.

Nos experimentos de calagem superficial com mais de duas amostragens de solo, observa-se a freqüência al eatória de acordo com o tempo (Oliveira \& Pavan, 1996; Pöttker \& Ben, 1998; Caires et al., 2000; Mello et al., 2003) e existem amostragens com intervalos sistemáticos, adotando-se a projeção aritmética de 6-12-18 meses (Rheinheimer et al., 2000a) ea projeção geométrica de 30-60-90-180-360 dias e de 6-18-36-48 meses (Rheinheimer et al., 2000b; Amaral \& Anghinoni, 2001).

Por outro lado, as análises estatísticas das características químicas do solo, considerando o fator quantitativo (com mais de três doses de calcário), apesar de inadequadas, segundo Santos et al. (1998), seguem as análises de variância com testes de comparações de médias para cada uma das épocas de amostragem de solo (Pöttker \& Ben, 1998; Castilhos et al., 2000; Rheinheimer et al., 2000b; Moreira et al ., 2001), à exceção de Caires et al . (2000) e Amaral \& Anghinoni (2001) que utilizaram análises de regressões para o ajuste das características químicas de acordo com as doses de cal cário e tempo de amostragem. A hipótese deste estudo é de que a freqüência sistemática da amostragem de solo, após os períodos de menor e maior precipitação, poderia ser determinante nas alterações das características da cal agem superficial .

O objetivo do presente estudo foi avaliar as alterações das características químicas promovidas pela calagem superficial, considerando as épocas de preci pitação e o tempo, em diferentes profundidades de um Latossolo Vermel ho distrófico.

\section{MATERIAL E MÉTODOS}

O experimento foi instalado na propriedade do Sr. J oão Pasquali, localizada no município de Alto Paraná, regiãonoroestedo Paraná (aproximadamente 
a $23^{\circ} 05^{\prime}$ S, $52^{\circ} 26^{\prime}$ W, $490 \mathrm{~m}$ ), em $20 / 10 / 99$. O solo corresponde a um Latossolo Vermel ho distrófico textura média (E mbrapa, 1999), com declividade de $0,04 \mathrm{~m} \mathrm{~m}^{-1}$. O clima na região é subtropical (Cfa), com predominância de verão quente, baixa freqüência de geadas, concentração de chuvas no verão entre outubro e março, com 100 a 200 mm mensais, sem estação seca definida, com precipitações de 25 a $100 \mathrm{~mm}$ de abril a setembro, à exceção de maio com $125 \mathrm{~mm}$, total izando precipitações anuais de 1.400 a $1.600 \mathrm{~mm}$ de acordo com as Cartas Climáticas do Paraná (IAPAR, 2000).

A área experimental vinha sendo explorada com braquiária (Brachiaria decumbens Stapf), tendo a reforma de pastagem em 1997/98 consistido no cultivo de mandioca sem o uso de fertilizantes ou corretivo de solo. Em maio de 1999, foi instalado um pomar da variedade de Iaranja Folha Murcha [Citrus sinensis (L.) Osbeck] enxertada sobreolimão Cravo (Citrus limonia Osbeck), no espaçamento de 3,8 x 6,8 m, por meio do cultivo em faixas (Auler et al., 2001). Esse cultivo consistiu da dessecação da Brachiaria decumbens com herbicida em faixas de $1,5 \mathrm{~m}$, nas quais foi realizado o preparo do solo (aração com grade pesada e escarificação), seguido do sulcamento para o plantio das mudas de laranjeira, mantendo-se a pastagem remanescente nas entrel inhas do pomar. Foi realizada a aplicação de 1,2 t ha-1 de calcário dolomítico nos sulcos de plantio das mudas de laranjeira. No quadro 1, são apresentados os resultados da análise química da camada de 0-0,20 m das entrelinhas do pomar de laranja de acordo com o método descrito por Pavan et al. (1992), caracterizando baixa fertilidade e elevada acidez, com 29,8 \% de saturação por alumínio $(m)$, considerando os padrões defertilidade desses sol os descritos por Fidalski (1997). A camada de solo de 0-0,20 m de profundidade pertence à classe textural arenosa (teores de argila inferiores a $150 \mathrm{~g} \mathrm{~kg}^{-1}$ ), segundo os resultados das análises granulométricas, determinadas pelo método da pipeta (E mbrapa, 1979, 1999), e à classe textural média (teores de argila entre 150 e $350 \mathrm{~g} \mathrm{~kg}^{-1}$ ) na profundidade de 0,20-0,60 m (Quadro 2).

O delineamento experimental utilizado foi em blocos ao acaso com quatro doses de calcário dolomítico em três repetições. Foram aplicadas doses de cal cário de $0,2,7,5,3$ e 8,0 t ha-1 de cal cário dolomítico comercial (PRNT, PN, ER, CaO, MgO, respectivamente, 91, 106, 96, 29 e $22 \%$ ), equivalentes às doses de $0,2,4,4,8$ e 7,2 t ha-1 corrigidas para poder relativo deneutralização total de $100 \%$, e a elevação da saturação por bases (V) para 68, 117 e $167 \%$, considerando a saturação por bases inicial de $18 \%$ (Quadro 1). As parcelas experimentais apresentavam área de $310 \mathrm{~m}^{2}$, constituídas de 15 plantas (três linhas de cinco plantas), sendo destinada a área das entrelinhas das três plantas centrais para as coletas das amostras de solo.

Em 19/10/99, a Brachiaria decumbens foi roçada mecanicamente para facilitar a distribuição do calcário, a qual foi realizada em 20/10/99, manualmente e a lanço, sobre a superfície das parcelas, sem incorporação. Amostragens de solo foram efetuadas nas áreas das entrelinhas (Brachiaria decumbens), cada amostra composta por seis subamostras, nas camadas de $0-0,05,0,05-0,10$, $0,10-0,20,0,20-0,40$ e 0,40-0,60 m, em duas épocas, nos anos de 2000 até 2002. As épocas de amostragens foram após o período de maior preci pitação (em 09/03/00, 23/04/01, 07/05/02), eapós o período de menor precipitação (em 30/10/00, 24/ 10/01, e 20/11/02), correspondendo aos 4, 12, 18, 24, 31 e 37 meses após a calagem. As amostragens foram realizadas com a umidade próxima à capacidade de campo, cerca de 2 a 3 dias após precipitações pluviais que umedeceram a profundidade do sol o superior à amostrada.

Para evitar contaminação das amostras de solo com o cal cário, as amostras de sol o foram col etadas com cilindros de 4,0, 3,5 e 3,0 pol egadas de diâmetro, respectivamente, para as três primeiras camadas, enquanto as duas últimas camadas foram col etadas com trado sonda de uma pol egada. Foram obtidas as determinações de $\mathrm{pH}$ em $\mathrm{CaCl}_{2}, \mathrm{H}+\mathrm{Al}(\mathrm{pH} \mathrm{SMP})$, $\mathrm{Ca}^{2+}$ e $\mathrm{Mg}^{2+}$ em KCl $1 \mathrm{~mol} \mathrm{~L}^{-1}, \mathrm{~K}$ pelo método Mehlich-1, de acordo com Pavan et al. (1992), os quais foram utilizados para a obtenção dos valores desaturação por bases. O manejo de sol o empregado nas entrelinhas do pomar de laranjeira durante o experimento restringiu-se à utilização de roçada mecânica para o controle da vegetação nas entrelinhas da cultura da Iaranjeira, que resultou na predominância de Brachiaria decumbens, homogênea em todas as parcelas experimentais e sem a presença de plantas invasoras.

\section{Quadro 1. Características químicas do Latossolo Vermelho distrófico, na camada de 0,00-0,20 m, antes da instalação do experimento}

\begin{tabular}{|c|c|c|c|c|c|c|c|c|c|}
\hline $\mathbf{P}$ & C & pH & $\mathrm{Al}^{3+}$ & $\mathbf{H}+\mathbf{A l}$ & $\mathrm{Ca}^{2+}$ & $\mathbf{M g}^{2+}$ & $K$ & $\mathbf{v}$ & m \\
\hline $\mathrm{mg} \mathrm{dm}^{-3}$ & $\mathrm{~g} \mathrm{dm}^{-3}$ & $\mathrm{CaCl}_{2}$ & 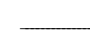 & 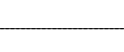 & $\mathrm{nol}_{\mathrm{c}} \mathrm{dm}$ & 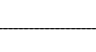 & - & 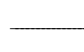 & 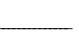 \\
\hline 6,40 & 5,70 & 4,10 & 0,37 & 3,97 & 0,60 & 0,13 & 0,14 & 18,0 & 29,8 \\
\hline
\end{tabular}


Quadro 2. Granulometria e classe textural nas cinco camadas amostradas do Latossolo Vermel ho distrófico

\begin{tabular}{ccccc}
\hline Profundidade & Argila & Silte & Areia & Classe textural(1) \\
\hline$m$ & & $g^{-1}$ & & \\
$0,00-0,05$ & 113 & 10 & 877 & Arenosa \\
$0,05-0,10$ & 123 & 10 & 867 & Arenosa \\
$0,10-0,20$ & 137 & 10 & 853 & Arenosa \\
$0,20-0,40$ & 170 & 10 & 820 & Média \\
$0,40-0,60$ & 183 & 13 & 804 & Média \\
\hline
\end{tabular}

(1) Embrapa (1999).

Na figura 1, são apresentadas as precipitações pluviais mensais no período de realização do experimento, podendo verificar as diferenças da intensidade de distribuição entre os períodos de maior e menor precipitação. O somatório das preci pitações e do número de dias que antecederam cada uma das amostragens de solo está indicado nessa figura.

A plotagem da acumulação da precipitação e do número de dias, crescentes da primeira à sexta amostragem de solo, apresentou um coeficiente de correl ação de 0,997 euma reta expressa pela equação (Precipitação $=104,31+3,93$ dias) (Figura 2 ), estimando-se uma preci pitação anual de $1.539 \mathrm{~mm}$, pertencente ao intervalo de preci pitação das cartas Climáticas do Paraná (APAR, 2000). I sto significa que, durante o experimento, não houve limitações hídricas severas para a dissolução do cal cário aplicado na superfície do solo, considerando a distribuição e a quantidade de preci pitação pluvial (Figuras 1 e2).

Os dados resultantes das características quími cas do solo $\mathrm{pH}, \mathrm{H}+\mathrm{Al}, \mathrm{Ca}^{2+}, \mathrm{Mg}^{2+} \mathrm{eV}$ foram submetidos

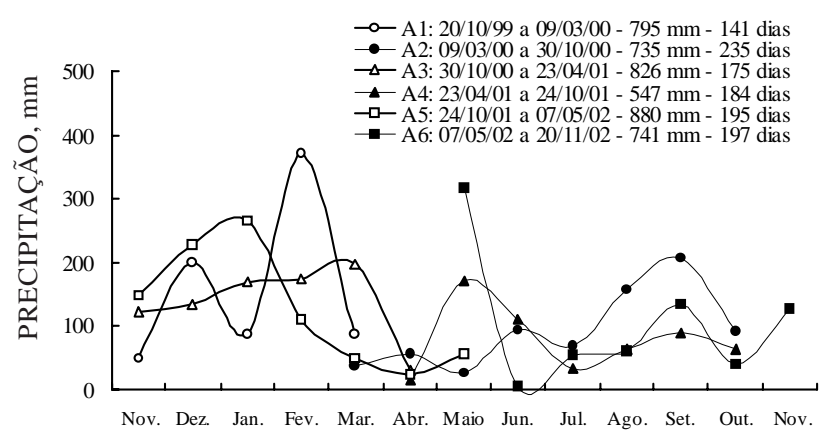

MÊS

Figura 1. Precipitações pluviais mensais no período do experimento de 20/10/1999 a 20/10/2002, obtidas da Estação Agrometeorológica de Paranavaí, localizada na Estação Experimental do Instituto Agronômico do Paraná (IAPAR), distante $15 \mathrm{Km}$ da área experimental. A1 a A6 correspondem ao somatório das preci pitações e do número de dias que antecederam cada uma das seis amostragens de solo.

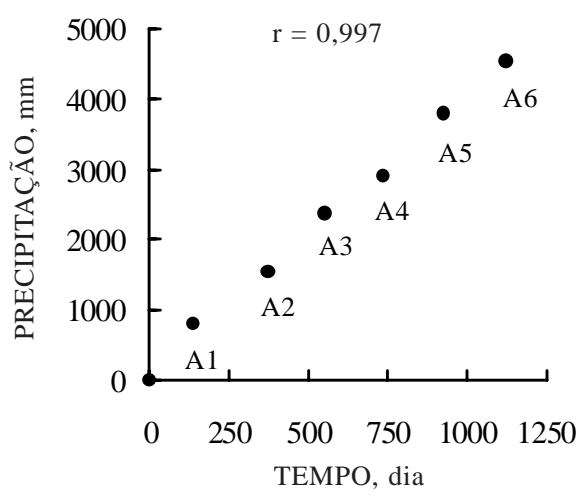

Figura 2. Acumulação das precipitações pluviais mensais de acordo com a acumulação do número de dias, para cada uma das seis amostragens no período do experi mento de 20/ 10/1999 a 20/10/2002. A1 a A6 correspondem ao somatório das precipitações e do número de dias que antecederam cada uma das seis amostragens de solo apresentadas na figura 1.

à análise de variância e de regressão por terem apresentado distribuição normal para a mai oria das épocas e camadas de solo. A análise de variância do delineamento experimental foi de blocos ao acaso no esquema de parcelas subsubdivididas com medidas repetidas no tempo de acordo com Banzatto \& Kronka (1989), Campos (1984) e Rezende et al. (1999). Na parcela, foi considerado o fator ano com três níveis (2000, 2001 e 2002); nas subparcelas, o fator época de amostragem com dois níveis (menor e maior preci pitação) e, nas subsubparcelas, o fator doses de cal cário com quatro níveis (doses de 0; 2,4; 4,8 e 7,2 t ha-1), de acordo com modelo matemático descrito por Gomez \& Gomez (1984), procedimento este utilizado individualmente para cada uma das cinco camadas de solo. Em seguida, foram verificadas as interações significativas a $5 \%$ pelo teste $\mathrm{F}$, em ordem decrescente das combinações dos fatores ano, época de amostragem e dose.

Para a análise de regressão foi adotada a técnica dos polinômios ortogonais descrita por Banzatto \& Kronka (1989), foram montados quadros auxiliares 
com causas de variação com um grau de liberdade para a regressão linear, a regressão quadrática e o desvio de regressão, tendo sido os quadrados médios divididos por um dos três resíduos obtidos por meio da análise devariância das parcelas subsubdivididas. A seleção da regressão foi realizada após a constatação de que não havia significância do desvio de regressão a $5 \%$ pel o teste $F$, seguida da seleção da regressão na ordem de seqüência quadrática ou linear, e determinando-se o coeficiente de determinação ajustado $\left(\overline{\mathrm{R}}^{2}\right)$.

De posse dos modelos matemáticos: linear e quadrático, foram determinadas as doses de cal cário que promoveram a máxima alteração sobre o pH, $\mathrm{H}+\mathrm{Al}, \mathrm{Ca}^{2+}, \mathrm{Mg}^{2+}$ e $\mathrm{V}$, sendo o modelo linear correspondente ao plateau e o quadrático obtido ao igualar a primeira derivada a zero, de acordo com Alvarez V. (1994). Para interpretar os resultados, foram plotadas as doses de calcário de acordo com cada uma das características químicas do solo, variando o número de model os de regressão em cada figura, dependendo dos resultados das análises de regressões no tempo (ano) e em profundidade por camada de solo. Desse modo, as figuras com os modelos de regressões permitem descrever a di nâmica das alterações das características químicas do solo promovidas pela calagem superficial .

\section{RESULTADOS E DISCUSSÃO}

O ajuste dos dados aos modelos de regressões lineares e quadráticos permitiu a descrição das alterações, considerando diferentes profundidades do sol o para $\mathrm{pH}$, acidez potencial $(\mathrm{H}+\mathrm{Al}), \mathrm{Ca}^{2+}, \mathrm{Mg}^{2+}$ e saturação por bases (V) (F iguras 3, 4, 5, 6, 7 e 8) (equações de regressões lineares e quadráticas numeradas de 1 a 22). Nessas figuras, pôde ser observada a evolução dos teores de $\mathrm{Ca}^{2+}$ na profundidade de $0-0,10 \mathrm{~m}$, dos valores de $\mathrm{pH}$ e $\mathrm{H}+\mathrm{Al}$ a 0,05- 0,20 m de profundidade, da saturação por bases a 0-0,20 $\mathrm{m}$ de profundidade e do $\mathrm{Mg}^{2+} \mathrm{a}$ $0-0,60 \mathrm{~m}$ de profundidade. A maior influência temporal ocorreu entre os anos de amostragem, destacando-se o $\mathrm{pH}, \mathrm{H}+\mathrm{Al} \mathrm{e} \mathrm{Mg}^{2+}$ no primeiro ano (2000), $\mathrm{pH}, \mathrm{H}+\mathrm{Al}, \mathrm{Mg}^{2+}$ e V no segundo e terceiro ano (2001 e 2002), enquanto os teores de $\mathrm{Ca}^{2+}(0-$ $0,10 \mathrm{~m})$ e de $\mathrm{Mg}^{2+}(0,40-0,60 \mathrm{~m})$ foram ajustados de acordo com a dose de cal cário. independentemente dos três anos de amostragem de solo.

O efeito da época de amostragem influenciou somente o ajuste dos dados da época de maior precipitação para os valores de $\mathrm{V}$ na profundidade de $0-0,05 \mathrm{~m}$, os quais independeram do ano de amostragem de solo. Esses resultados comprovam a eficiência da calagem superficial no perfil do solo estudado, sendo superior à profundidade de 00,05 m, encontrada por Pöttker \& Ben (1998), Castilhos et al. (2000) e Petrere \& Anghioni (2001), corroborando os resultados obtidos na profundidade de $0-0,10 \mathrm{~m}$ por Rheinheimer et al. (2000b) e de 0-0,15 m por Rheinheimer et al. (2000a) e Ciotta et al. (2004), além de terem confirmado as alterações químicas a 0,20-0,40 m de profundidade, de acordo com os resultados descritos por Oliveira \& Pavan (1996) e a 0-0,60 m descritos por Caires et al. (2000) e Gatiboni et al. (2003).

A correção da acidez do sol o no primeiro ano após a calagem (2000) foi descrita matematicamente na camada de 0,05-0,10 m, constatada pela equação de regressão linear para o pH (Figura 3, Equação 4). Nessa camada de solo, no segundo ano (2001, Equação 2), o modelo de regressão quadrático indicou o máximo valor de $\mathrm{pH}$ 5,41 para a dose de 6,6 t ha-1 de calcário. Constatou-se que, nesse mesmo ano, ocorreu o início da correção do pH na camada de 0,10-0,20 m (Figura 3, Equação 5). A evolução da correção da acidez do solo foi contínua no tempo e, no terceiro ano (2002, Equação 1), na camada de 0,05-0,10 m, o pH elevou-se para um valor máximo de 6,1 com 6,4 t ha-1 de calcário, enquanto, na camada de $0,10-0,20$ m deste ano, a equação de regressão linear (E quação 3) indicava a reação do calcário nessa camada pelo aumento crescente dos valores de $\mathrm{pH}$ decorrente das doses de calcário distribuídas na superfície do solo. Tais resultados contrariam os estudos de calagem superficial que apresentaram alterações do pH restritoà camada de 0-0,05 m (Pöttker \& Ben, 1998; Castilhos et al., 2000; Rheinheimer et al., 2000a; Moreira et al. 2001) e corroboram os estudos de Petrere \& Anghinoni (2001), Oliveira \& Pavan (1996) eCaires et al. (2000) que constataram alterações dos valores de $\mathrm{pH}$ nas camadas subsuperficiais, podendo atingir até 0,60 $\mathrm{m}$ de profundidade.

Os estudos de cal agem superficial geralmentenão consideram a acidez potencial $(\mathrm{H}+\mathrm{Al})$ para descrever a superfície de resposta dessa variável de acordo com as doses de cal cário, à exceção de Caires et al. (2000). Tal procedimento estatisticamente permite o ajuste matemático indireto dos dados de $\mathrm{Al}^{3+}$, os quais isol adamenteinviabilizariama análise de regressão em razão da ocorrência de valores nulos nas camadas superficiais após a calagem. No primeiro ano (2000, Equação 6), a acidez potencial respondeu linear e negativamente às doses de cal cário, enquanto, no terceiroano (2002, E quações 7 e 8), observou-se efeito quadrático da calagem na redução dos val ores de H + Al para valores de 2,15 e $2,99 \mathrm{cmol}_{\mathrm{c}} \mathrm{dm}^{-3}$, respectivamente, nas camadas de $0,05-0,10$ e 0,10-0,20 m e doses máximas de 6,1 e 6,7 t ha-1 $^{-1}$ de cal cário (Figura 4).

Os teores máximos de Ca ${ }^{2+}$ de 1,89 e 0,89 $\mathrm{cmol}_{C} \mathrm{dm}^{-3}$ foram obtidos com as doses de 5,7 e 6,4 t ha-1 de cal cário, respectivamente, para as camadas de 0-0,05 e 0,05-0,10 m (Figura 5, Equações 9 e 10). Por outro lado, os teores de $\mathrm{Mg}^{2+}$ no primeiro ano (2000) aumentaram linearmente com as doses de cal cário distribuído na superfície do solo nas camadas de 
Equação 1: 0,05-0,10 m, em 2002,

$\hat{y}=4,3500+0,5382 x-0,0420 x^{2} ; R^{2}=0,9849$

Equação 2: 0,05-0,10 m, em 2001,

$\hat{y}=4,2817+0,3431 x-0,0260 x^{2} ; R^{2}=0,8757$

Equação 3: 0,10-0,20 m, em 2002,

$\hat{y}=4,2917+0,0833 x ; R^{2}=0,9803$

Equação 4: 0,05-0,10 m, em 2000,

$\hat{y}=4,1750+0,0590 x ; R^{2}=0,9109$

Equação 5: 0,10-0,20 m, em 2001, $\hat{y}=4,1350+0,0319 x ; R^{2}=0,9945$

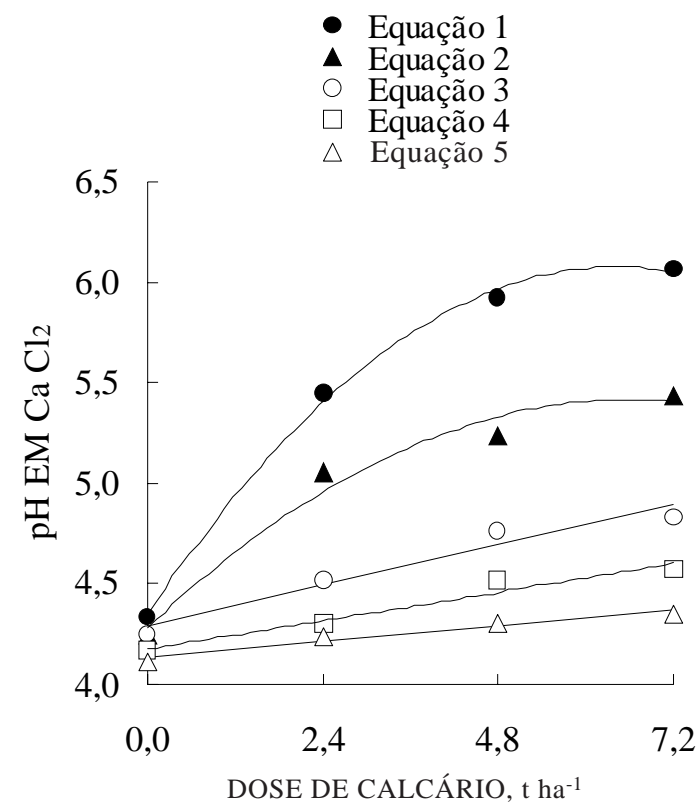

Figura 3. Valores de $\mathrm{pH}$ em $\mathrm{CaCl}_{2}$ de acordo com as doses crescentes de calcário distribuído na superfície do solo em 1999. As equações de regressões (linear e quadrática) variam de acordo com as camadas de solo $(0,05-0,10$ e 0,10-0,20 m) e anos de amostragem (2000, 2001 e 2002).

0,05-0,10 e 0,10-0,20 m, (Figura 6, Equações 14 e 16). No segundo ano (2001, Equação 12), observouse, na camada de 0,05-0,10 m, que o teor máximo de $0,85 \mathrm{cmol}_{\mathrm{c}} \mathrm{dm}^{-3}$ de $\mathrm{Mg}^{2+}$ demandou 6,0 t ha-1 de calcário, enquanto, na camada subjacente de 0,100,20 m (Equação 15), ainda estava ocorrendo resposta linear às doses de cal cário. J á no terceiro ano (2002, Equações 11 e 13), nas camadas de 0,050,10 e 0,10-0,20 m, observam-se os teores máximos de 1,05 e $0,67 \mathrm{cmol}_{c} \mathrm{dm}^{-3}$ de $\mathrm{Mg}^{2+}$, para os quais seriam necessárias doses de 6,3 e 7,7 tha-1 de calcário, respectivamente. Nas camadas de 0,200,40 e 0,40-0,60 m, para elevar os teores máximos de $\mathrm{Mg}^{2+}$ de 0,19 e 0,14 $\mathrm{cmol}_{\mathrm{c}} \mathrm{dm}^{-3}$, foi necessária a aplicação, respectivamente, de 6,1 e 4,5 t ha-1 de calcário na superfície do solo (Figura 7, Equações 17 e 18). Observou-se que o teor de $\mathrm{Mg}^{2+}$ no perfil de $0-0,60$ m consistiu na característica química do solo que melhor descreveu a evolução da eficiência da calagem superficial no perfil do solo (F iguras 6 e 7).

As alterações diferenciadas do $\mathrm{Ca}^{2+} \mathrm{e} \mathrm{Mg}^{2+}$ no perfil do solo diante das alterações do $\mathrm{pH}$ e $\mathrm{H}+\mathrm{Al}$ na camada de 0,10-0,20 m estão associadas aos aumentos dos teores de $\mathrm{Mg}^{2+}$ (Figuras 3, 4, 5, 6 e 7). As justificativas utilizadas para explicar a mobilidade desses cátions diante da baixa solubilidade do cal cário distribuído na superfície do solo atualmente estão fundamentadas na decomposição desses resíduos vegetais que formariam complexos orgânicos hidrossolúveis (ácidos orgânicos de baixo peso molecular) capazes de formarem complexos com $\mathrm{Ca}^{2+}, \mathrm{Mg}^{2+}$ e $\mathrm{Al}^{3+}$, aumentando a dissolução do calcário e a sua mobilidade no perfil do solo (Rheinheimer et al., 2000b; Amaral \& Anghioni (2001), Moreira et al., 2001, Petrere\& Anghinoni, 2001; Ciotta et al., 2004), mecanismo este descrito por Franchini et al. (1999).

Equação 6: 0,05-0,10 m, em 2000,

$$
\hat{y}=3,6123-0,0782 x ; R^{2}=0,9999
$$

Equação 7: 0,10-0,20 m, em 2002,

$$
\hat{y}=3,7995-0,2436 x+0,0182 x^{2} ; R^{2}=0,9970
$$

Equação 8: 0,05-0,10 m, em 2002,

$$
\hat{y}=3,6384-0,4906 x+0,0403 x^{2} ; R^{2}=0,9609
$$

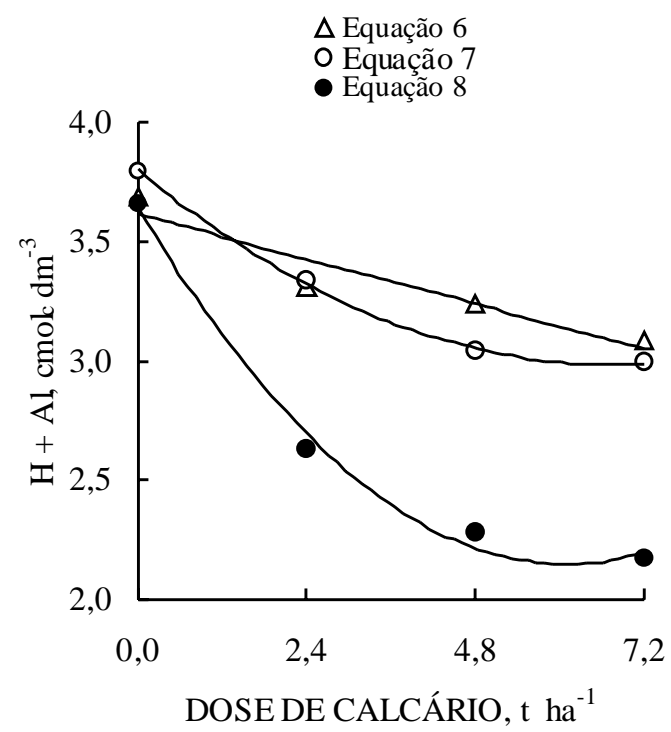

Figura 4. Valores de acidez potencial $(\mathbf{H}+\mathrm{Al})$ de acordo com as doses crescentes de calcário distribuído na superfície do solo em 1999. As equações de regressões (linear e quadrática) variam de acordo com as camadas de solo $(0,05-$ 0,10 e 0,10-0,20 m) e anos de amostragem (2000, 2001 e 2002). 
Equação 9: 0-0,05 m, em 2000, 2001 e 2002, $\hat{\mathrm{y}}=0,9821+0,3157 \mathrm{x}-0,0275 \mathrm{x}^{2} ; \mathrm{R}^{2}=0,9884$

Equação 10: 0,05-0,10 m, em 2000, 2001 e 2002, $\hat{y}=0,4841+0,1288 x-0,0101 x^{2} ; R^{2}=0,9999$

- Equação 9

○ Equação 10

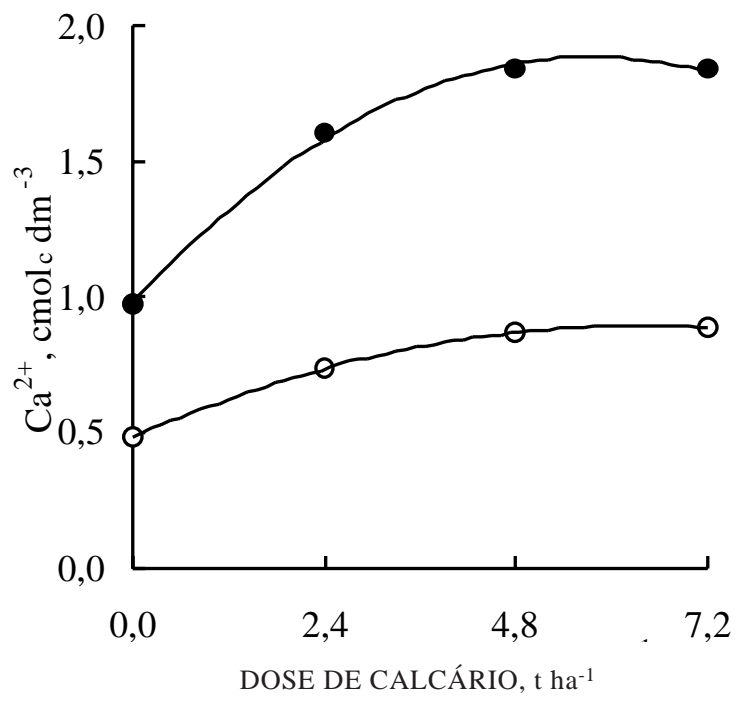

Figura 5. Teores de $\mathrm{Ca}^{2+}$ de acordo com as doses crescentes de calcário distribuído na superfície do solo em 1999. As equações de regressões (linear e quadrática) variam de acordo com as camadas de solo (0-0,05 e 0,05-0,10 m) anos de amostragem (2000, 2001 e 2002).

Considerando que a amostragem do solo foi realizada sob a vegetação da Braquiaria decumbens e controlada por meio de roçada mecânica nas entrelinhas do pomar de laranja, houve, durante o período de estudo, a contínua formação de resíduos vegetais por essa gramínea que podem ter contribuído para a maior mobilidade do $\mathrm{Mg}^{2+}$ no perfil do solo comparada ao $\mathrm{Ca}^{2+}$. Contudo, deveuse considerar a menor eficiência das espécies de pastagens como as gramíneas Paspal um notatum e Cynodon nlenfuensis no mecanismo da mobilidade de hidrossolúveis, comparada à da aveia preta e tremoço azul, conforme estudo realizado por M eda et al. (2001).

A máxima saturação por bases de 66 \% foi obtida na camada de 0-0,05 m, com 5,9 t ha-1 de calcário. A época de amostragem de solo após o período de maior precipitação (Figura 8, Equação 19) deveu-se à inexistência de limitação de água no solo para a dissolução das partículas de calcário nos períodos queantecederam essas amostragens (F iguras 1 e 2). A hipótese deste estudo, qual seja, o efeito da época de amostragem decorrente da precipitação, não se confirmou nas demais camadas e características químicas do solo por causa da significância dos resíduos dos desvios da regressão. Considerando a evol ução das al terações das características químicas do solo (Figuras 3, 4, 5, 6, 7 e 8), acredita-se que o $\mathrm{pH}, \mathrm{H}+\mathrm{Al}$ e $\mathrm{Mg}^{2+}$ tenham apresentado a máxima alteração de seus valores na camada de 0-0,05 m, antes da segunda amostragem de solo, de modo que não houve significância no ajuste dos dados destas características químicas nesta camada de solo, dada a semelhança dos valores máximos às diferentes doses de cal cário distribuído na superfície do solo.

Equação 11: 0,05-0,10 m, em 2002,

$$
\hat{y}=0,2775+0,2472 x-0,0197 x^{2} ; R^{2}=0,9775
$$

Equação 12: 0,05-0,10 m, em 2001, $\hat{y}=0,2412+0,2033 x-0,0169 x^{2} ; R^{2}=0,9290$

Equação 13: 0,10-0,20 m, em 2002, $\hat{y}=0,1350+0,1389 x-0,0090 x^{2} ; R^{2}=0,9984$

Equação 14: 0,05-0,10 m, em 2000, $\hat{y}=0,1610+0,0452 x ; R^{2}=0,9988$

Equação 15: 0,10-0,20 m, em 2001, $\hat{y}=0,1367+0,0347 x ; R^{2}=0,8874$

Equação 16: 0,10-0,20 m, em 2000, $\hat{y}=0,1515+0,0048 x ; R^{2}=0,9104$

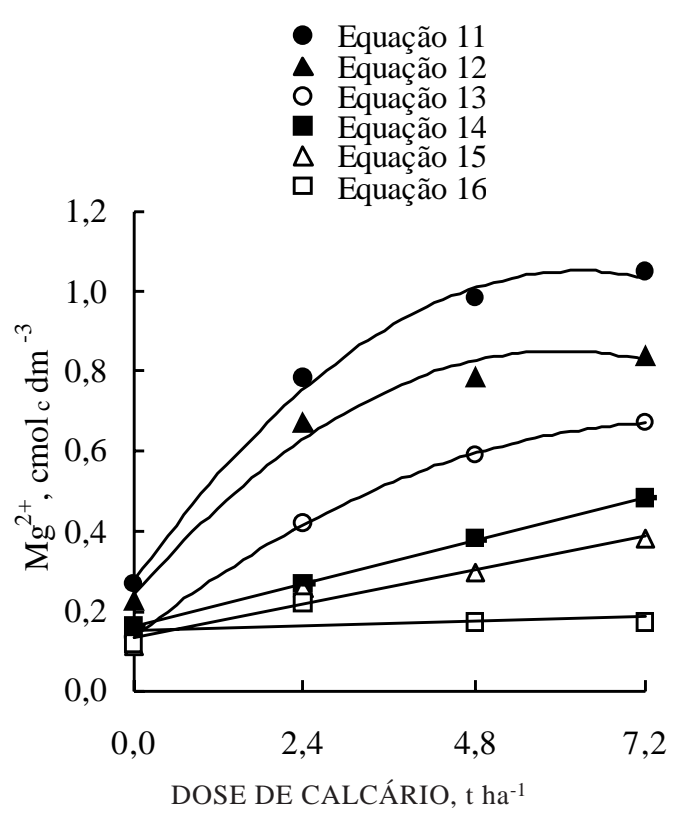

Figura 6. Teores de $\mathrm{Mg}^{2+}$ de acordo com as doses crescentes de calcário distribuído na superfície do solo em 1999. As equações de regressões (linear e quadrática) variam de acordo com as camadas de solo $(0,05-0,10$ e 0,10-0,20 m) e anos de amostragem (2000, 2001 e 2002). 
Equação 17: 0,20-0,40 m, em 2000, 2001 e 2002, $\hat{y}=0,1099+0,0258 x-0,0021 x^{2} ; R^{2}=0,8189$

Equação 18: 0,40-0,60 m, em 2000, 2001 e 2002, $\hat{\mathrm{y}}=0,0729+0,0312 \mathrm{x}-0,0035 \mathrm{x}^{2} ; \mathrm{R}^{2}=0,6992$

- Equação 17

• Equação 18

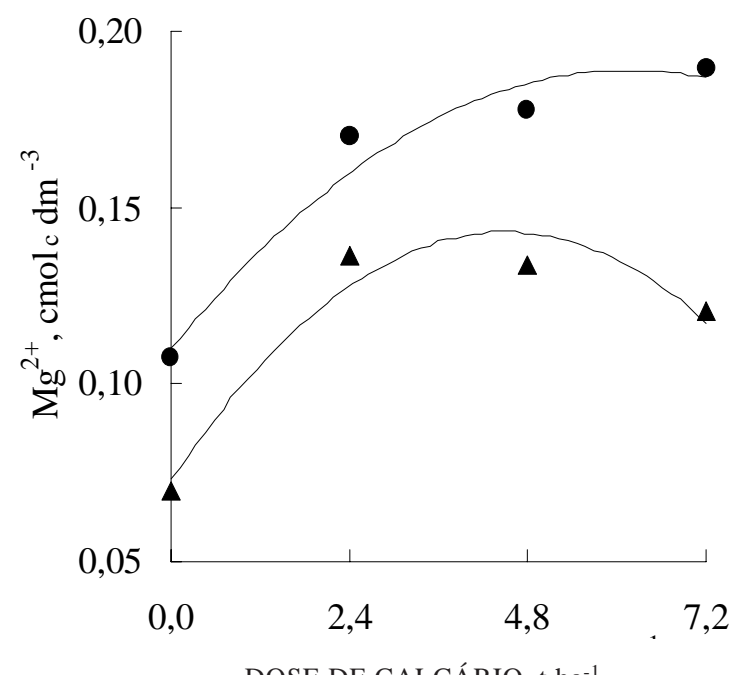

DOSE DE CALCÁRIO, $\mathrm{t} \mathrm{ha}^{-1}$

Figura 7. Teores de $\mathrm{Mg}^{2+}$ de acordo com as doses crescentes de calcário distribuído na superfície do solo em 1999. As equações de regressões (linear e quadrática) variam de acordo com as camadas de solo $(0,20-0,40$ e 0,40-0,60 m) e anos de amostragem (2000, 2001 e 2002).

Tais resultados são respaldados por Amaral \& Anghinoni (2001), ao terem constatado a dissolução do calcário aos 90 dias, com base nos valores de condutividade elétrica de $\mathrm{Ca}^{2+} \mathrm{e} \mathrm{M} \mathrm{g}^{2+}$ na solução do solo, em um estudo de calagem superficial em plantio direto.

Contudo, os resultados do presente estudo divergem dos resultados obtidos por Meda et al. (2002) quanto ao pequeno efeito da calagem superficial em colunas de solo na profundidade de 0-0,05 $\mathrm{m}$ para o $\mathrm{pH}, \mathrm{Ca}^{2+}$ e $\mathrm{Mg}^{2+}$, revelando que o estudo em condições de laboratório, com amostra de solo deformada e submetida à lixiviação com água destilada, não possi bilitou a si mulação das condições naturais do solo e que a utilização de amostras de solo deformadas pode comprometer a eficiência da calagem superficial nesses solos que apresentam textura arenosa na camada de 0-0,20 m (Quadro 2).

A constatação da influência da precipitação e da dissolução do cal cário distribuído na superfície do solo confronta-se com o possível transporte de calcário através da chuva que poderia ser um mecanismo importante na cor reção da aci dez do sol o em profundidade no sistema plantio direto, de acordo com Amaral et al. (2004a). Este mecanismo de mobilidade do cal cário pela água da chuva deve ser considerado diante da constatação de Amaral et al . (2004b), ao não detectar nenhum tipo de ácido orgânico de baixo peso molecular tanto na solução percolada como na solução do solo, não tendo os resíduos orgânicos apresentado efeitos na correção da acidez do solo em profundidade. Conyers et al. (2003) corroboram esta afirmação ao atribuírem a menor eficiência da calagem superficial a 0,05-0,10 m, na Austrália, comparada ao estudo de Oliveira \& Pavan (1996), no Brasil, a 0-0,40 m, enfatizando a diferença da precipitação anual de $570 \mathrm{~mm}$ na Austrália comparada aos $1.500 \mathrm{~mm}$ no Brasil, semelhantes às apresentadas no presente estudo (Figura 2), apesar do mai or poder-tampão do solo brasileiro. Uma das prováveis causas ainda não exploradas experimentalmente em condições de

$$
\begin{aligned}
& \text { Equação 19: } 0-0,05 \mathrm{~m} \text { em } 2000,2001 \text { e } 2002 \text {, na } \\
& \text { época de maior precipitação, } \\
& \hat{y}=41,1322+8,4713 \mathrm{x}-0,7235 \mathrm{x}^{2} ; \mathrm{R}^{2}=0,9335 \\
& \text { Equação 20: } 0,05-0,10 \mathrm{~m} \text {, em } 2000,2001 \text { e } 2002 \text {, } \\
& \hat{\mathrm{y}}=19,0227+6,8254 \mathrm{x}-0,5178 \mathrm{x}^{2} ; \mathrm{R}^{2}=0,9722
\end{aligned}
$$

Equação 21: 0,10-0,20 m, em 2002, $\hat{y}=17,1163+2,2676 x ; R^{2}=0,9986$

Equação 22: 0,10-0,20 m, em 2001, $\hat{y}=15,7310+1,0386 x ; R^{2}=0,9033$

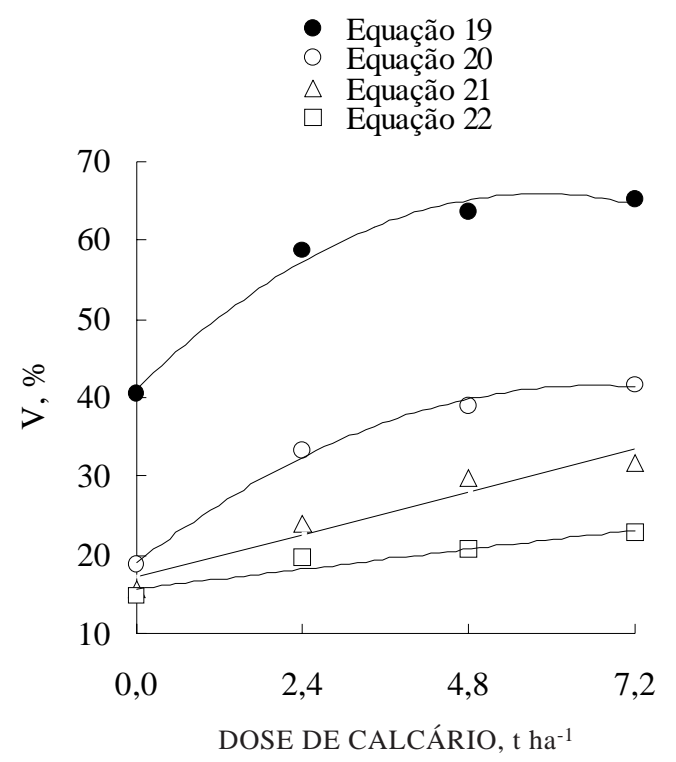

Figura 8. Valores de saturação por bases (V) de acordo com as doses crescentes de calcário distribuído na superfície do solo em 1999. As equações de regressões (linear e quadrática) variam de acordo com as camadas de solo $(0,05-$ 0,10 e 0,10-0,20 m) época e anos de amostragem (2000, 2001 e 2002). 
campo é o efeito da biomassa vegetal verde e em decomposição na manutenção diferenciada do teor de água, os quais determinariam a dissolução e a mobilidade do cal cário distribuído na superfície do solo.

Independentemente dos mecanismos que possam estar interagindo na dissolução e na mobilidade do cal cário distribuído na superfície do solo, a dinâmica diferenciada entre os teores de $\mathrm{Ca}^{2+}$ e $\mathrm{Mg}^{2+}$ (Figuras 5, 6 e 7) apresenta coerência, quando foi caracterizado o desequilíbrio desses cátions no perfil do solo, os quais implicaram a redução da relação $\mathrm{Ca}^{2+} / \mathrm{Mg}^{2+}$ no perfil do solo decorrente das doses de cal cário(Figura 9). Nessa figura, é possível observar a evolução decrescente da relação $\mathrm{Ca}^{2+} / \mathrm{Mg}^{2+}$ em função das doses crescentes de cal cário distribuído na superfície do solo nos três anos de amostragem de solo, principalmente nas camadas de 0,10-0,20 e 0,20-0,40 m (Figura 9a,b,c). Nas camadas de 0-0,05, $0,05-0,10,0,10-0,20,0,20-0,40$ e $0,40-0,60 \mathrm{~m}$ do terceiro ano (2002), são observadas as menores relações de $\mathrm{Ca}^{2+} / \mathrm{Mg}^{2+}$ para as três doses de cal cário, respectivamente, de 1,38, 1,18, 1,06, 2,61 e 3,67. Esses resultados revelam que o maior decréscimo da relação $\mathrm{Ca}^{2+} / \mathrm{Mg}^{2+}$ ocorreu na camada de 0,10$0,20 \mathrm{~m}$, caracterizando o mai or incremento de $\mathrm{Mg}^{2+}$ nessa camada de solo em detrimento do $\mathrm{Ca}^{2+}$, vindo a confirmar os resultados da estagnação dos val ores de $\mathrm{Ca}^{2+}$ nas camadas subjacentes de 0-0,05 e 0,05$0,10 \mathrm{~m}$. N esse contexto, Oliveira \& Pavan (1996) e Caires et al. (2000) não exploraram o efeito dos cátions, apesar de terem verificado as alterações conjuntamente desses cátions a 0,40 e $0,60 \mathrm{~m}$ de profundidade. Por outrolado, Gatiboni et al . (2003) eCiotta et al. (2004), ao analisarem separadamente os dados de $\mathrm{Ca}^{2+}$ e $\mathrm{Mg}^{2+}$, concluíram que as alterações ocorreram nas mesmas camadas de solo para o $\mathrm{Ca}^{2+}$ e $\mathrm{Mg}^{2+}$, porém em profundidades inferiores àquelas em que ocorreu a redução dos teores de $\mathrm{Al}^{3+}$.
Constatada a correção da acidez na camada superficial do solo (Figura 8, E quação 20), verificouse a máxima alteração do valor de saturação por bases (42\%) também na camada de 0,05-0,10 m, independentemente dos anos, com a dose máxima de 6,6 t ha-1 decal cário. Este processo de correção é contínuo no tempo e espaço, visto que, na camada de 0,10-0,20 m (Figura 8, Equações 21 e 22), as equações de regressões lineares indicam a contínua el evação dos valores de saturação por bases de acordo com as doses de calcário no segundo e no terceiro ano (2001 e 2002). Além de constituir a característica química de maior importância para a determinação da necessi dade de calagem, esta foi a única característica química do sol o que apresentou o ajuste dos dados de $V$ aos model os matemáticos de regressão nas camadas de 0-0,05, 0,05-0,10 e $0,10-0,20 \mathrm{~m}$, ou seja, incorporou todos os efeitos do $\mathrm{pH}, \mathrm{H}+\mathrm{Al}, \mathrm{Ca}^{2+} \mathrm{eMg}^{2+}$ na profundidade de 0,20 m.

As al terações das características quími cas do solo no tempo e em profundidade indicam que, no segundo ano (2001), houvea máxima al teração para a maioria das características estudadas expressa pelas equações de regressões quadráticas na profundidade de $0-0,10 \mathrm{~m}$, e de que, no terceiro ano (2002), as equações de regressões lineares acusavam o estabel eci mento de uma frente dealcal inização na camada subjacente a $0,10-0,20 \mathrm{~m}$. Rheinheimer et al. (2000b) também descreveram o avanço dos efeitos da calagem superficial que só ocorreu após a neutralização da camada de aplicação ou da al cançada pela migração.

Tais resultados vêm confirmar que o ajuste das características químicas do sol o aos model os lineares e quadráticos por meio da análise de variância em parcela subsubdividida notempo permitiu descrever a dinâmica da eficiência da calagem superficial no tempoe por camada desolo empiricamente apontada por Fidalski et al. (2002) nesse solo: rápida na

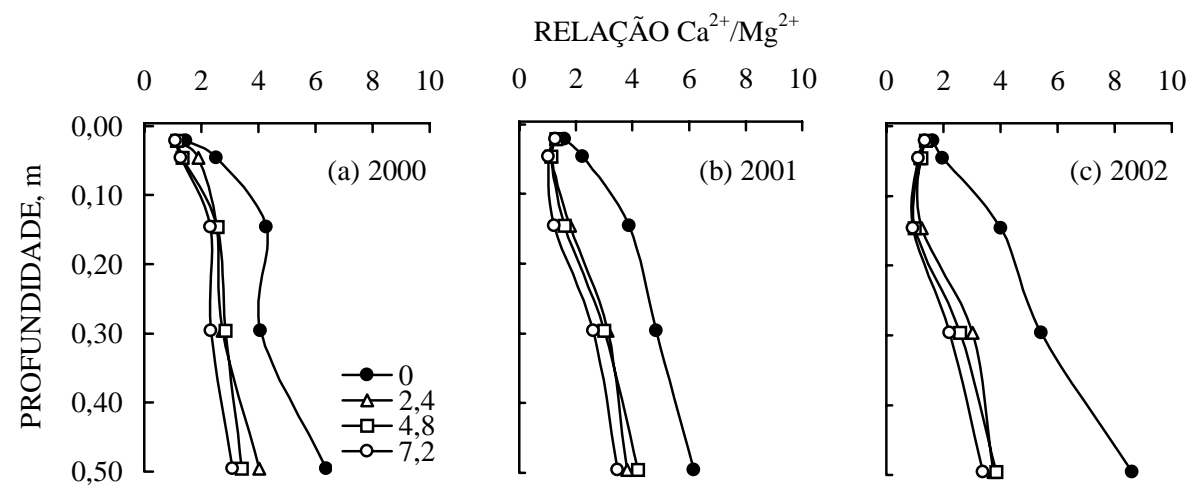

Figura 9. Relação média entre os teores de $\mathrm{Ca}^{2+} \mathrm{e} \mathrm{Mg}^{2+}$ de acordo com a profundidade de solo nas camadas intermediárias de 0-0,05, 0,05-0,10, 0,10-0,20, 0,20-0,40 e 0,40-0,60 m de profundidade, paras as doses de $0,2,4,4,8$ e 7,2 $\mathrm{t} \mathrm{ha}^{-1}$ de calcário distribuído na superfície do solo em 1999, para as amostragens de solo realizadas em 2000 (a), 2001 (b) e 2002(c). 
camada de 0-0,05 m, moderada na camada de $0,05-0,10 \mathrm{~m}$ e lenta na camada de 0,10-0,20 m. Neste sentido, estes resultados corroboram os resultados deAmaral \& Anghinoni (2001), indicando que a reaplicação do cal cário na superfície do solo em plantio direto apresentou efeitos considerados relativamente rápidos sobre as características químicas do solo no prazo de 360 dias para a profundidade de $0,04 \mathrm{~m}$.

As alterações das características químicas do solo dependeram de elevadas doses de calcário, superiores a 5,9 t ha-1 ${ }^{-1}$ na camada de 0-0,20 m, sendo este val or mínimo determinado para a saturação por bases na camada de 0-0,05 m (F igura 8). Esta dose de cal cário corresponderia ao dobro da necessidade decalagem pel o método de saturação por bases para uma profundidade de $0,20 \mathrm{~m}$ e os resultados das análises químicas do solo antes do experimento (Quadro 1), ou seja, essa dose de calcário corresponderia a um V de $140 \%$. A dinâmica da calagem obtida no presente experimento mostra a utilização de doses de cal cário levemente superior à necessidade obtida para um $\mathrm{V}$ de $70 \%$, correspondendo à dose de $2,5 \mathrm{t} \mathrm{ha}^{-1}$ semelhante à primeira dose de cal cário utilizada de 2,4 t ha-1.

Considerando a utilização dessa dose de cal cário, seria possível descrever apenas um terço dos modelos matemáticos de regressões, não sendo possível determinar os valores máximos para cada uma das características químicas estudadas, porque não se atingiria o ponto de inflexão dos modelos de regressões quadráticas. Tal fato permite explicar a inexpressiva alteração das características químicas desses solos nos estudos de calagem realizados anteriormente por Machado et al. (1979), Rêgo, (1997), Fidalski (1999) e Meda et al. (2002).

De modo geral, nos experimentos de calagem superficial baseada no método saturação por bases, as doses de calcário limitaram a sua el evação no intervalo de 60 e 90 \% (Oliveira \& Pavan, 1996; Caires et al., 2000; Moreira et al., 2001; Mello et al., 2003; Oliveira et al., 2003), ligeiramente superior à necessidade máxima decalagem para a maioria das culturas comerciais agrícolas. Estes resultados evidenciam a importância da revisão das atuais doses de calcário que vêm sendo utilizadas nos experimentos de calagem superficial.

Contudo, não se recomenda a utilização da dose mínima de 5,9 t ha-1 obtida para descrever as máxi mas alterações das características químicas do solo. I sto acarretaria uma supercalagem superficial que poderia causar deficiências nutricionais de Zn e $B$, a exemplo do que foi constatado por Pavan (1992) nas fol has de macieira. Caires et al . (2000) indicam a calagem superficial somente quando o solo apresentar pH inferior a 5,6 ou uma saturação por bases inferior a $65 \%$ na camada de 0-0,05 m. Com basenestecritério, justificar-se-iam as recomendações de parcelar a dosagem de calcário e aumentar a freqüência da calagem superficial proposta para a correção da acidez e nutrição dos citros por $\mathrm{Ca}^{2+} \mathrm{e}$ $\mathrm{Mg}^{2+}$ (Fidalski \& Auler, 1997; Fidalski et al., 1999, 2000).

A eficiência da reaplicação da calagem superficial em intervalos de um a oito anos foi verificada por Pöttker \& Ben (1998), Rheinheimer et al. (2000b), Gatiboni et al. (2003) e Ciotta et al. (2004). Esta eficiência se deve à formação de uma frente de alcalinização que avança no perfil do solo proporcional mente à dose de cal cário distribuído na superfície e ao tempo (Rheinheimer et al., 2000b; Gatiboni et al., 2003). Para sol os com características semel hantes aos deste estudo, com baixo podertampão, os resultados indicam a importância do estabelecimento e da manutenção da frente de al cal inização em sistemas de culturas permanentes, tais como: a citricultura e a pastagem, por meio da reaplicação da cal agem superficial de acordo com as recomendações técnicas e exigências nutricionais de cada cultura, monitorada pela amostragem de solo na camada de 0-0,10 e 0,10-0,20 m de profundidade, com doses que calcário de acordo com as recomendações técnicas e exigências nutricionais de cada cultura.

\section{CONCLUSÕES}

1. A máxima alteração das características químicas do solo foi obtida a partir de doses de calcário superiores ao dobro da necessidade de calcário, convencionalmente determinada pelo método de saturação por bases para el evá-loa $70 \%$, na profundidade de $0,20 \mathrm{~m}$. A utilização de el evadas doses de calcário distribuída na superfície do solo foi adequada para determinar a máxima alteração das características químicas do solo por meio de model os de regressão quadrática.

2. A amostragem de sol o após o período de maior precipitação foi indispensável ao ajuste dos dados da saturação por bases na camada de 0-0,05 m. Deste modo, considera-se importante observar, na época de amostragem, a distribuição das precipitações pluviais e conteúdo de água no solo para o estudo do mecanismo de mobilidade do calcário no perfil do solo.

3. As alterações dos teores de $\mathrm{Ca}^{2+}$ limitaram-se à camada de $0-0,10 \mathrm{~m}$, enquanto os teores de $\mathrm{Mg}^{2+}$ apresentaram progressivamente do primeiro ao terceiro ano a 0-0,60 m de profundidade. Os teores de $\mathrm{Mg}^{2+}$ mantiveram-se associados à correção da acidez do solo ( $\mathrm{pH}$ eH $+\mathrm{Al}$ ) e a el evação dos valores de saturação por bases na profundidade de $0,10-0,20 \mathrm{~m}$, na qual foi constatada a menor relação $\mathrm{Ca}^{2+}$ $\mathrm{Mg}^{2+}$ igual a 1,06, independentemente da dose de calcário.

4. A máxima resposta da calagem superficial ocorreu no terceiro ano e na camada de 0-0,10 m 
caracterizada pel os modelos deregressão quadrática, momento em que se identificou o estabelecimento de uma frente de alcalinização na camada de 0,10-0,20 m por meio dos model os de regressãolinear. O método empregado de parcelas subsubdivididas no tempo permitiu a descrição da dinâmica da calagem no perfil do solo de acordo com o tempo.

\section{LITE RATURA CITADA}

ALVAREZ V., H.V. Avaliação da fertilidade do solo: superfícies de resposta, modelos aproximativos para expressar a relação fator-resposta. Viçosa, Universidade Federal de Viçosa, 1994. 75p.

AMARAL, A.S. \& ANGHINONI, I. Alteração de parâmetros químicos do solo pela reaplicação superficial de cal cário no sistema plantio direto. Pesq. Agropec. Bras., 36:695-702, 2001.

AMARAL, A.S.; ANGHINONI, I.; HINRICHS, R. \& BERTOL, I. Movimentação de partículas de calcário no perfil de um Cambissolo em plantio direto. R. Bras. Ci. Solo, 28:359367, 2004a.

AMARAL, A.S.; ANGHINONI, I. \& DESCHAMPS, F.C. Resíduos de plantas de cobertura e mobilidade dos produtos da dissolução do cal cário aplicado na superfície do solo. R. Bras. Ci. Solo, 28:115-123, 2004b.

AULER, P.A.M.; FIDALSKI, J ; PAVAN, M.A. \& J ACOMINO, A.P. Preparo do solo em faixa sobre área de pastagem e manejo das entrelinhas na formação da Iaranja Pêra. In: CONGRESSO BRASILEIRO DE CIÊNCIA DO SOLO, 28., Londrina, 2001. Anais. Londrina, Sociedade Brasileira de Ciência do Solo, 2001. p.292.

BANZATTO, D.A. \& KRONKA, S.N. Experimentação agrícola. J aboticabal, FUNEP, 1989. 247p.

CAIRES, E.F.; BANZATTO, D.A. \& FONSECA, A.F. Calagem na superfície em sistema plantio direto. R. Bras. Ci. Solo, 24:161-169, 2000.

CASTILHOS, Z.M.S.; FREITAS, J.M.O. \& GUTTERRES, J . Aplicação superficial de calcário e adubação numa pastagem nativa. Pesq. Agropec. Gaúcha, 6:181-187, 2000.

CAMPOS, H. Estatística aplicada à experimentação com canade-açúcar. São Paulo, FEALQ, 1984. p.151-230.

CIOTTA, M.N.; BAYER,C.; ERNANI, P.R; FONTOURA, S.M.V.; WOBETO, C. \& ALBURQUERQUE, J.A. Manejo da calagem e os componentes da acidez de Latossolo Bruno em plantio direto. R. Bras. Ci. Solo, 28:317-326, 2004.

CONYERS, M.K.; HEENAN, D.P.; MCGHIE, W.J . \& POILE, G.P. Amelioration of acidity with time by limestone under constrasting tillage. Soil Till. Res., 72:85-94, 2003.

EMPRESA BRASILEIRA DE PESQUISA AGROPECUÁRIA EMBRAPA. Serviço Nacional de Levantamento e Conservação de Solos. Manual de métodos de análise de solo. Rio de J aneiro. 1979. (Método 1.17)

EMPRESA BRASILEIRA DE PESQUISA AGROPECUÁRIA EMBRAPA. Centro Nacional de Pesquisa de Solos (Rio de J aneiro). Sistema brasileiro de classificação de solos. Brasília. Embrapa Produção de I nformação; Rio deJ aneiro, Embrapa Solos, 1999. 412p.
FAQUIN, V.; HOFFMANN, C.R.; EVANGELISTA, A.R. \& GUEDES, G.A.A. O potássio e o enxofre no crescimento da braquiária e do colonião em amostras de um Latossolo da região Noroeste do Paraná. R. Bras. Ci. Solo, 19:87-94, 1995.

FIDALSKI, J . Fertilidade do sol o sob pastagens, lavouras anuais e permanentes na região noroeste do Paraná. R. Unimar, 19:853-861, 1997.

FIDALSKI, J . Respostas da mandioca à adubação NPK ecalagem em solos arenosos do noroeste do Paraná. Pesq. Agropec. Bras., 34:1353-1359, 1999.

FIDALSKI, J \& \& AULER, P.A.M. Levantamento nutricional de pomares de Iaranja no noroeste do Paraná. Arq. Biol. Tecnol., 40:443-451, 1997.

FIDALSKI, J .; PAVAN, M.A.; AULER, P.A.M. \& J ACOMINO, A.P. Produção de frutos de laranjeira Pêra e teores de nutrientes nas fol has e no solo, em Latossolo VermelhoEscuro do noroeste do Paraná. R. Bras. Ci. Solo, 23:273279, 1999.

FIDALSKI, J ;; AULER, P.A.M. \& TORMEM, V. Relations among Valencia orange yields with soil and leaf nutrients in northwestern Paraná, Brazil. Arq. Biol. Tecnol., 43:387391, 2000.

FIDALSKI,J .; MIYAZAWA, M.; PAVAN, M.A.;AULER, P.A.M.; TORMENA, C.A. \& DE MARTIN, G.L. Eficiência do calcário aplicado na superfície de um Latossolo Vermelho distrófico, originário do arenito Caiuá do Paraná. In: REUNIÃO BRASILEIRA DE MANEJ O E CONSERVAÇÃO DO SOLO E DA ÁGUA, 14., Cuiabá, 2002. Anais. Cuiabá, UFMT, 2002. CD-ROM

FRANCHINI, J.C.; MALAVOLTA, E.; MIYAZAWA, M. \& PAVAN , M.A. Alterações químicas em solos ácidos após a aplicação de resíduos vegetais. R. Bras. Ci. Solo, 23:533542, 1999.

GATIBONI, L.C.; SAGGIN, A.; BRUNETTO, G.; HORN, D.; FLORES, J .P.C.; RHEINHEIMER, D.S. \& KAMINSKI, J . Alterações nos atributos químicos de solo arenoso pela calagem superficial no sistema plantio direto consolidado. Ci. Rural, 33:283-290, 2003.

GOMES, J .C. Considerações sobre adubação e calagem para a cultivar de mandioca. R. Bras. Mandioca, 6:99-107, 1987.

GOMEZ, K.A. \& GOMEZ, A.A. Three or more factor experiments: split-split-plot design. In: GOMEZ, K. A. \& GOMEZ, A.A., eds. Statistical procedures for agricultural research. 2.ed. New York, J ohn Wiley \& Sons, 1984. p.139153.

HOFFMANN, C.R.; FAQUIN, V.; GUEDES, G.A.A. \& EVANGELISTA, A.R. O nitrogênio e o fósforo no crescimento da braquiária e do colonião em amostras de um Latossolo da região noroeste do Paraná. R. Bras. Ci. Solo, 19:79-86, 1995.

INSTITUTO AGRONÔMICO DO PARANÁ - IAPAR. Cartas climáticas do Paraná: edição ano 2000, versão 1.0. Londrina, IAPAR, 2000. CD-ROM

MACHADO, M.L.S.; MELLA, S.C.; CUNHA, A.M. \& MUZILLI, O. Avaliação de gramíneas promissoras em três níveis de fertilidade e em presença e ausência de cal cário no noroeste do Paraná. In: REUNIÃO ANUAL 16., Curitiba, 1979. Anais. Curitiba, Sociedade Brasileira de Zootecnia, 1979. v.2, 360p. 
MEDA, A.R.; PAVAN, M.A.; CASSIOLATO, M.E.; PAVAN, M.A. \& MIYAZAWA, M. Alleviating soil acidity through plant organic compounds. Arq. Biol. Tecnol., 44:185-189, 2001.

MEDA, A.R.; PAVAN, M.A.; CASSIOLATO, M.E. \& MIYAZAWA, $M$. Dolomite lime's reaction applied on the surface of a sandy soil of the northwest Paraná, Brazil. Arq. Biol. Tecnol., 45:219-222, 2002.

MELLO, J .C.A.; VILLAS BÔAS, R.L.; LIMA, E.V.; CRUSCIOL, C.A.C. \& BÜLL, L.T. Alterações nos atributos químicos de um $L$ atossol o distroférrico decorrentes da granulometria e doses de calcário em sistemas plantio direto e convencional. R. Bras. Ci. Solo, 27:553-561, 2003.

MOREIRA, S.G.; KIEHL,J .C.; PROCHNOW, L.I \& \& PAULETTI, $V$. Calagem em sistema de semeadura direta e efeitos sobre a acidez do solo, disponibilidade de nutrientes e produtividade demilho esoja. R. Bras. Ci. Solo, 25:71-81, 2001.

OLIVEIRA, E.L. \& PAVAN, M.A. Control of soil acidity in notillage system for soybean production. Soil Till. Res., 38:4757, 1996.

OLIVEIRA, P.P.A.; BOARETTO, A.E.; TRIVELIN, P.C.O.; OLIVERIRA, W.S. \& CORSI, M. Liming and fertilization to restore degraded Brachiaria decumbens pastures grown on an Entisol. Sci. Agric., 60:125-131, 2003.

PAVAN, M.A. Manejo da calagem em pomares estabel ecidos de macieira. Pesq. Agropec. Bras., 27:271-276, 1992.

PAVAN, M.A.; BLOCH, M.F.; ZEMPULSKI, H.C.; MIYAZAWA, M. \& ZOCOLER, D.C. Manual de análise química do solo e controle de qualidade. Londrina, IAPAR, 1992. 40p. (IAPAR. Circular, 76)

PETRERE, C. \& ANGHINONI, I. Alteração de atributos químicos no perfil do solo pela calagem superficial em campo nativo. R. Bras. Ci. Solo, 25:885-895, 2001.
PÖTTKER, D. \& BEN, J.R. Calagem para uma rotação de culturas no sistema plantio direto. R. Bras. Ci. Solo, 22:675684, 1998.

QUAGGIO, J.A. Análise de solo para citros: Métodos e critérios para a interpretação de resultados. In: SEMINÁRIO INTERNACIONAL DE CITROS, 4., Bebedouro, 1996. Anais. Campinas, Fundação Cargill, 1996. p.95-113.

RÊGO, I.C. Calagem e gessagem num Latossolo VermelhoEscuro cultivado com laranjeira Pêra sobre limoeiro Cravo. Piracicaba, Universidade de São Paulo, CE NA/USP, 1997. 94p. (Tese de Doutorado)

REZENDE, D.M.L.C.; FERREIRA, D.F.; MUNIZ, J.A. \& AQUINO, L.H. Comparações de técnicas de análises de experimentos utilizando medidas repetidas no tempo. Ci. Agrotec., 23:928-938, 1999.

RHEINHEIMER, D.S.; SANTOS, E.J.S.; KAMINSKI, J. \& XAVIER, F.M. Aplicação superficial de cal cário no sistema plantio direto consolidado em solo arenoso. Ci. Rural, 30:263-268, 2000a.

RHEINHEIMER, D.S.; SANTOS, E.J .S.; KAMINSKI, J .; BORTOLUZZI, E.C. \& GATIBONI, L.C. Alterações de atributos do solo pela calagem superficial e incorporada a partir de pastagem natural. R. Bras. Ci. Solo, 24:797-805, 2000b.

SÁ, J .P.G. \& CAVIGLIONE, J.H. Arenito Caiuá: capacidade de lotação das pastagens. Londrina, IAPAR, 1999. 15p. (IAPAR. I nforme da Pesquisa, 132)

SANTOS, J.W.; MOREIRA, J.A.N. \& BELTRÃO, N.E.M. Aval iação do emprego dos testes de comparação de médias na Revista Pesquisa Agropecuária Brasileira (PAB) de 1980 a 1994. Pesq. Agropec. Bras., 33:225-230, 1998. 
